\title{
ENTRE FILOSOFÍA Y POLÍTICA. PLATÓN EN LA CONDICIÓN HUMANA DE HANNAH ARENDT
}

\author{
Daniel Brito-García \\ Universidad Austral de Chile. Valdivia. Chile
}

\begin{abstract}
Resumen: Considerando la hostil relación entre filosofía y política propuesta en la antigüedad por Platón, el presente trabajo intenta adentrarse en dicha línea desde el tratamiento de Hannah Arendt a partir de una de sus obras fundamentales: $L a$ condición humana. Estimamos que en esta obra es posible captar lo medular de las preocupaciones arendtianas en torno a esta tensa relación, pudiendo proyectar desde ese lugar sus vicisitudes en otras de sus obras que contemplan la inquietud por el fundamento de esta y su dinámica complejidad. Arendt ve en Platón la clave para entender hostilidad entre ambas disciplinas y, en diálogo con su figura, intentaremos adentrarnos en las reflexiones concernientes al problema y sus derivas.
\end{abstract}

Palabras claves: Filosofía - política - pensamiento - contemplación - acción

\section{BETWEEN PHILOSOPHY AND POLITICS. PLATO IN THE HUMAN CONDITION OF HANNAH ARENDT}

\begin{abstract}
Considering the hostile relationship between philosophy and politics proposed in antiquity by Plato, this paper attempts to delve into this line from the treatment of Hannah Arendt from one of his fundamental works: The human condition. We estimate that in this work it is possible to capture the core of the Arendtian concerns about this tense relationship, being able to project from this place its vicissitudes in other works that contemplate the concern for the foundation of this and its dynamic complexity. Arendt sees in Plato the key to understand hostility between both disciplines and, in dialogue with his figure, we will try to get into the reflections concerning the problem and its drifts.
\end{abstract}

Keywords: Philosophy - politics - thought - contemplation - action

Recibido: 31.05.2019 - Aceptado: 31.03.2020 
Correspondencia: Daniel Brito-García

Estudiante de Doctorado en Ciencias Humanas mención Discurso y Cultura, Universidad Austral de Chile (UACH). Becario CONICYT, folio 21191246

Email: danieleugeniobritogarcia@gmail.com

Dirección institucional: Universidad Austral de Chile, Campus Isla Teja, Independencia 631, Valdivia, Chile

"El puesto que la política ocupó en la filosofía estaba determinado sobre todo por la afirmación platónica de que la $\pi \rho \bar{\alpha} \xi 1 \varsigma$ de alguna manera está más lejos de la verdad que la $\theta \varepsilon \omega \rho i ́ \alpha "$

Hannah Arendt, Diario filosófico, Cuaderno XII, diciembre de 1952 [16].

\section{Introducción ${ }^{1}$}

7 Dodos los esfuerzos teóricos de Hannah Arendt estuvieron orientados a esclarecer tan solo una problemática: la hostil

1 relación entre filosofía y política. Es conocida la entrevista realizada en 1964 por Günter Gaus en la que él agradece la distinción establecida por ella entre "el ser humano como ser que filosofa y el ser humano como ser que actúa". Dicha distinción manifiesta renovada vitalidad en la obra arendtiana, aun cuando los especialistas siempre han intentado clasificarla como una "filósofa política", lo que se reveló aceptar debido a que su principal interés fue "contemplar la política con ojos, ..., no enturbiados por la filosofía" (Arendt, 2010, p. 43). De ahí que la "teoría política”, y no la "filosofía política" -pesada categoría cuya tradición la autora se niega a cargar en sus hombros-, haya sido su preocupación primera (2016a, p. 119 - 122).

$1 \quad$ Las ideas fundamentales del presente trabajo fueron expuestas en la ponencia brindada en el marco del VI Congreso Internacional de Estudios Griegos "Grecia y los otros. El mundo helénico y su relación con otros pueblos a través de su historia: visiones, reflexiones, encuentros y perspectivas", organizado por el Centro de Estudios Griegos, Bizantinos y Neohelenos "Fotios Malleros" de la Universidad de Chile y por el Centro de Estudios Clásicos "Giuseppina Grammatico Amari" de la U.M.C.E, realizado en Santiago de Chile, entre los días 17 al 19 de octubre de 2018. 
En su difícil anhelo encontró diversos hitos, siendo uno de ellos el punto de quiebre entre las disciplinas en cuestión: Platón. En él, por primera vez y para siempre, se encarna la hostilidad entre filosofía y política. Leamos atentamente los siguientes pasajes para hacernos una idea sobre ello.

En el primero, Calicles insta a Sócrates a ponderar el encanto de la filosofía respecto de los asuntos humanos:

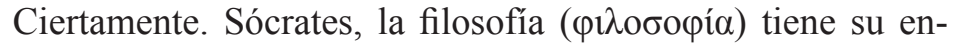
canto si se toma moderadamente en la juventud; pero si se insiste en ella más de lo conveniente es la perdición de los hombres ( $\delta 1 \alpha \varphi \theta 0 \rho \alpha ̀$ $\tau \tilde{\omega} v \dot{\alpha} v \theta \rho \omega ́ \pi \omega v)$. Por bien dotada que esté una persona, si sigue filosofando después de la juventud, necesariamente se hace inexperta de todo lo que es preciso que conozca el que tiene el propósito

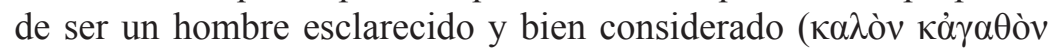

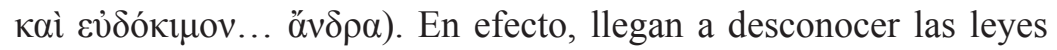
(vó $\mu \omega v)$ que rigen la ciudad ( $\pi$ ó $\lambda \mathrm{\imath v}$ ), las palabras $(\lambda o ́ \gamma \omega v)$ que se deben usar para tratar con los hombres en las relaciones privadas

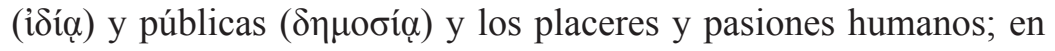
una palabra, ignoran totalmente las costumbres. Así pues, cuando

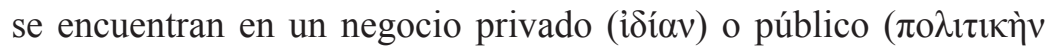
$\pi \rho \tilde{\alpha} \xi ı)$, resultan ridículos, del mismo modo que son ridículos, a

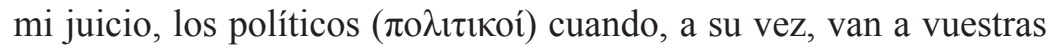

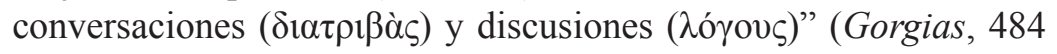
$\mathrm{c}-\mathrm{e})^{2}$.

Un segundo pasaje contenido en la República (VI, 500b - d) advierte la postura platónica sobre la división entre la filosofía y la política puesta en boca de Sócrates:

- Sin duda, Adimanto, cuando se tiene verdaderamente diri-

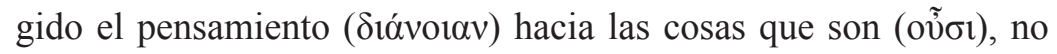

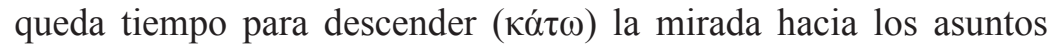
humanos ( $\alpha v \theta \rho \omega ́ \pi \omega v \pi \rho \alpha \gamma \mu \alpha \tau \varepsilon i ́ \alpha \varsigma)$ y ponerse en ellos a pelear, colmado de envidia y hostilidad; sino que, mirando y contemplando

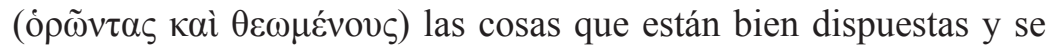
comportan siempre del mismo modo, sin sufrir ni cometer injusticia unas a otras, conservándose todas en orden (Кó $\sigma \mu \omega)$ y conforme

Véase Parménides 130a - e. Cf. Arendt 2014b, p. 173. 


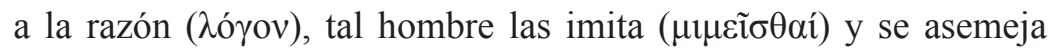
( $\dot{\alpha} \varphi$ o nismo por el cual aquel que convive con lo que admira no lo imite?

- Es imposible.

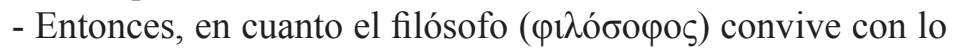

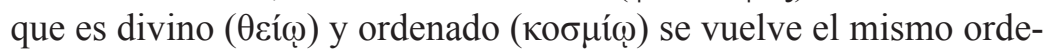

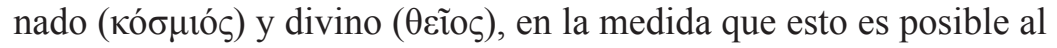
hombre ${ }^{3}$.

En un tercer y último pasaje ilustrativo lo encontramos nuevamente en República (VII, 521 b), ahora circunscrito al diálogo entre Glaucón y Sócrates en torno a un Estado bien gobernado:

- ¿Y sabes acaso de algún otro modo de vida, que el de la

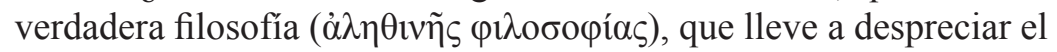
mando político ( $\pi \mathrm{o} \lambda \iota \tau \iota \kappa \tilde{\omega} \nu \dot{\alpha} \rho \chi \tilde{\omega} v)$ ?

- No, por Zeus.

- Es necesario entonces que no tengan acceso al gobierno

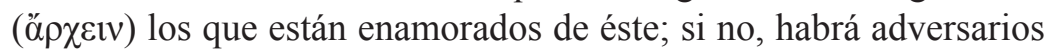
que los combatan.

- Sin duda.

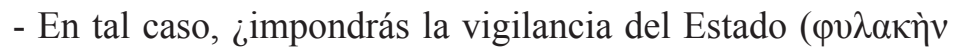
$\tau \tilde{\eta} \varsigma \pi$ ó $\lambda \varepsilon \omega \varsigma)$ a otros que a quienes, además de ser los más inteligentes ( $\varphi \rho \circ \imath \mu \omega ́ \tau \alpha \tau o \imath)$ en lo que concierne al gobierno del Estado ( $\pi$ ó $\lambda 1 \varsigma$

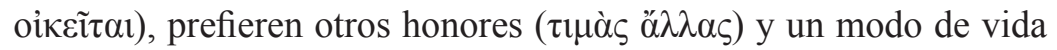
mejor que el del gobernante ( $\pi \mathrm{o} \lambda \iota \tau \iota \kappa o \tilde{)})$ del Estado?

- No, a ningún otro"4.

Desde Platón se materializa una tensa relación de fricción tal como es posible captar en estos pasajes. Arendt ve en él la bisagra que condensa la relación entre ambas disciplinas, disgregándolas y uniéndolas en forma compleja y dinámica. Si bien en ella influye de manera decisiva la cultura griega en general, y su pensamiento filosófico en particular, Platón posee un sitial fundamental. A partir de él su proyecto de teoría política y su visión crítica de la filosofía, y en particular de la filosofía política, cobra sentido (Arendt, 2016b, p. 33, p. 44). Pero en su grandeza radica su intrínseca

$3 \quad$ Cf. Arendt, 2014b, p. 102 - 114 y p. $115-120$.

$4 \quad$ Cf. República, I, 347b - e. 
dificultad: Platón sienta las bases de la filosofía y la política occidental, de la misma manera que las distingue hasta situarlas como opuestas; desde él la primera nunca será neutral refiriéndose a la segunda, al modo contrario de un filósofo cuando habla de la naturaleza 5 .

Lo anterior se origina a raíz del juicio, condena y muerte de Sócrates $^{6}$, referente de justicia y sabiduría para Platón y para toda la Grecia clásica $^{7}$, hecho que Arendt destaca desde el comienzo de su obra hasta su muerte en 1975. Con este hecho surge la hostilidad antes declarada por ambas disciplinas que previo al suceso parecían tener sana concordia. Esto marca un punto de inflexión que se cristaliza con la actitud platónica hacia ambas disciplinas, estableciendo una línea divisoria e infranqueable entre una y otra desde su raíz. Justamente este es el punto desde el que arranca el análisis arendtiano para desarrollar la problemática que atraviesa todo su recorrido intelectual de manera medular. Si bien Los orígenes del totalitarismo, obra que le otorga un lugar destacado en el círculo intelectual de la segunda mitad de siglo XX, abarca tangencialmente este problema y bajo pretextos distintos ${ }^{8}$, desde esa fecha en adelante comienza un inquietante camino en el que trata minuciosamente de dilucidar la relación entre filosofía y política9 . Dicho camino alcanza la cúspide en La condición humana (1958), obra en la que vierte todo su esfuerzo para diagnosticar, evidenciar, desplegar y corroborar el porqué de la relación compleja de las disciplinas mencionadas. Del análisis de esta obra emprenderemos la tarea de estudiar las tensiones que subyacen en el diagnóstico arendtiano referido a esta problemática.

$5 \quad$ Cf. Arendt, 2010, p. 43.

6 Para apreciar el perfil que Arendt establece en torno a la figura de Sócrates, véase Arendt, 1997, p. 11 - 64; 2014b, p. 189 - 202; 2016a, p. 43 - 75.

7 Cf. Cornford, 1950, p. 54; Guthrie, 1994a, p. 82/ 1994b, p. 394; Hegel, 1995, p. 99; Calvo Martínez, 2004, p. 121 - 122; Jaeger, 2006, p. 452 - 455, 479, 545 - 548; García Gual, 2017, p. 99 y 113. Véase Apología de Sócrates 31 d - 32 a; Carta $7 m a 324$ a - 326 b.

8 Cf. Arendt, 2011, p. 72 -73, 423, 455 - 456, 625.

9 Cf. Birulés (2007, p. 59 - 66); Campillo (2013, p. 39 - 44, p. 113 - 116, p. 152 - 166); Forti (2001, p. 39 - 52, p. 109 - 135, p. 137 - 160, p. 319 - 333); Mundo (2008, p. 137 - 152); Rilla (2008, p. 117 - 136). 


\section{1.- Vita activa versus vita contemplativa}

La primera tensión que intenta mostrar Arendt radica en la distinción entre vita activa y vita contemplativa, la que despliega a lo largo de toda su obra del 58' y que inmediatamente abre paso a su proyecto inconcluso orientado al estudio en detalle de esta última vita en La vida del espíritu. En La condición humana (Arendt, 2013, p. 37), examina la vita activa de forma pormenorizada, describiéndola como "la vida humana hasta donde se halla activamente comprometida en hacer algo, [la que] está siempre enraizada en un mundo de hombres y de cosas realizadas por éstos, que nunca deja ni trasciende por completo". Esta orienta su atención principalmente a la categoría de acción, aun cuando esta vita contempla tanto la labor, el trabajo y la acción misma. Para ella, las tres actividades resultan esenciales pues cada una corresponde a "las condiciones básicas bajo las que se ha dado al hombre la vida en la tierra" (Arendt, 2013, p. 21). Ello no quita el peso de la tradición a la expresión "vita activa", cuya data es tan antigua como la tradición de pensamiento político, la que justamente parte con el juicio de Sócrates y el conflicto que reside en su figura, el del filósofo y la polis (Arendt, 2009, p. 46 - 48, 76, 104; 2013, p. 25; 2016b, p. $170-$ 178, p. 180 - 183; 2018, p. 605 - 607). La expresión, propia de la filosofía medieval y heredera del bios politikos aristotélico (Ética nicomáquea, I, $5)^{10}$, ya aparece expuesta en De civitate Dei (XIX, 19, p. 605) de Agustín, entendida como la vida dedicada a los asuntos público-políticos en franca oposición a la vita contemplativa, cuyo punto de quiebre se da bajo el contexto de la desaparición de la antigua ciudad-estado ${ }^{11}$. Bajo este manto, la expresión pierde su especificidad política, implicando "toda clase de activo compromiso con las cosas de este mundo" (Arendt, 2013, p. 27).

Con esto, la acción fue considerada como una de las necesidades de la vida terrenal, siendo la contemplación el modo de vida verdaderamente libre con exclusividad. La superioridad de la contemplación, al margen de este dato, no es de origen cristiano, pues esto surge justamente con Platón ${ }^{12}$. Toda su filosofía política está dirigida por el discernimiento del

$10 \quad$ Cf. Arendt 2006, p. 277; 2013, p. 26.

11 Cf. Arendt 2014b, p. $174-175$.

12 Arendt (2016b, p. 184), refiriéndose a la dicotomía de la que se nutre la tradición del pensamiento político entre contemplación y acción, y de cómo esto entronca con Aristóteles y Platón en torno al comienzo de la filosofía, dice: "Aristóteles, aunque no acepta la doctrina platónica de las ideas, e incluso 
filósofo, solo teniendo presente hacer posible su modo de vida en la utópica organización de la polis, punto que se mantiene en Aristóteles, ahora en orden al ideal de contemplación $(\theta \varepsilon \omega \rho i ́ \alpha)$ (Ética nicomáquea, X, 7 - 8) ${ }^{13}$. Por esto, la expresión vita activa está en franca cercanía con lo que Aristó-

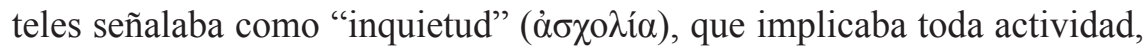
más que al bios politikos griego, y en notable distancia de la quietud de la contemplación, la cual fue sugerida por los filósofos frente a la libertad respecto de las necesidades de la vida y la coacción de los demás (Arendt habla del "cese de la actividad política ( $\sigma \chi 0 \lambda \eta ́) " 14$, con lo se que originó la filosofía apolitia de la antigüedad y la posterior actitud del cristianismo respecto de la liberación de los asuntos mundanos (2016a, p. 168). Así es como Arendt recalca con fuerza que toda clase de actividad debe terminar en la absoluta quietud de la contemplación, incluido el pensamiento: "cualquier movimiento del cuerpo y del alma, como del discurso y del razonamiento, han de cesar ante la verdad" (2013, p. 28). Aquí es imposible no recordar a Platón y su noción de pensamiento que ella también hace suya: el pensamiento es el diálogo entre "yo y yo mismo" (Gorgias, 482 c: "غ̇ $\mu \grave{\varepsilon}$ $\dot{\varepsilon} \mu \alpha v \tau \tilde{\varphi}$ ") $)^{15}$, el "discurso que el alma tiene consigo misma sobre las cosas

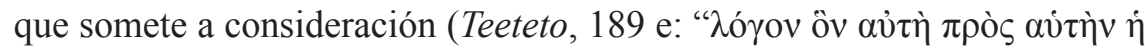

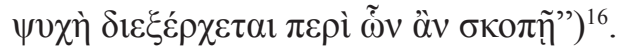

Tradicionalmente la convicción de la superioridad de la contemplación respecto de la acción se sustenta en que no existe trabajo igualable a

repudia el estado ideal platónico, no obstante lo sigue en lo primordial: por una parte, distingue entre un modo de vida teórico (ßíos $\theta \varepsilon \omega \rho \eta \tau$ «ós) y una vida

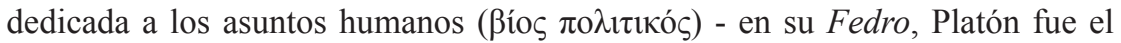
primero en establecer el orden jerárquico de esos modos de vida -, y, de otra, acepta como algo consabido el orden jerárquico implícito”. Cf. Fedro $277 \mathrm{~b}-278 \mathrm{e}$ como fundamento de este pasaje arendtiano y, revísese además el 246d - 248, con especial atención a $247 \mathrm{~d}$ - e, en el que se presenta la luminosa superioridad de la contemplación.

13 Cf. Arendt, 2013, p. 26 - 27. Véase. Gorgias, 484 c - 485 c; Fedón, 68 b - c; República, VI, 496 c - 497 a y IX, 592 a - b; Teeteto, 173 c - 176 e, 175 e.

14 Cf. Arendt, 2013, p. 27, nota 10.

15 Cf. Arendt, 2014b, p. 202 - 215; 2015a, p. 51 - 52; 2015b, p. 178; 2016a, p. 58.

16 Cf. Arendt, 2013, p. 80 - 81, 108, 186 - 188. Véase Sofista, 263 e. 
la "belleza y verdad del kosmos físico, que gira inmutable y eternamente sin ninguna interferencia del exterior, del hombre o dios" (Arendt, 2013, p. 28). De esta manera, se entiende que la expresión vita activa haya tomado su significado de la vita contemplativa, cuyo valor radicaría en nada más que servir a las exigencias de un cuerpo vivo en orden a la contemplación ${ }^{17}$. Si bien en el cristianismo se enarbola como bandera la gloria de la contemplación, esto coincidió con el grato descubrimiento de la contemplación como facultad humana que se dio desde Sócrates en adelante, cuya influencia se ha dejado notar en toda la tradición de pensamiento filosófico y político, y que se patentiza nítidamente en Platón, entendiendo la contemplación como experiencia de lo eterno. Por esto Arendt destaca que "solamente en Platón la preocupación por lo eterno y la vida del filósofo se ven como inherentemente contradictorias y en conflicto con la pugna por la inmortalidad, la forma de vida del ciudadano, el bios politikos" (2013, p. $32)^{18}$. Este punto es central en la discusión arendtiana, pues su análisis no está dirigido a negar la validez de la distinción entre una vita y otra, sino que más bien, se dirige a destacar que

El enorme peso de la contemplación en la jerarquía tradicional ha borrado las distinciones y articulaciones dentro de la vita activa $\mathrm{y}$ que, a pesar de las apariencias, esta condición no ha sufrido cambio esencial por la moderna ruptura con la tradición y la inversión final de su orden jerárquico en Marx y Nietzsche (Arendt, 2013, p. 29) ${ }^{19}$.

17 Citando a Hugo de Saint-Victor, Arendt reitera en La vida del espiritu (2014b, p. 32 - 33): "La forma de vida activa es $<<$ laboriosa $>>$, la contemplativa es pura quietud; la activa se despliega en público, la contemplativa en el $<<$ desierto $>>$; la activa se consagra a $<<$ la necesidad del prójimo $>>$, la contemplativa a la $<<$ visión de Dios $>>$ ". [...] He citado a un autor medieval del siglo XII, casi al azar, porque la idea de que la contemplación es el estado más elevado del espíritu es tan antigua como la filosofía occidental. La actividad pensante - según Platón, el diálogo silencioso que tenemos con nosotros mismos - solo sirve para abrir los ojos del espíritu, incluso el nous aristotélico es un órgano para ver y contemplar la verdad. En otras palabras, el pensamiento tiende a y culmina en la contemplación, y esta no es activa sino pasiva; es el punto donde la actividad mental descansa". Cf. 2014b, p 72.

19 Cf. Arendt, 2014b, p. 33. 
Situada su arriesgada apuesta y examinados algunos de sus logros alcanzados, pasemos a la siguiente tensión arendtiana en torno a la problemática relación entre filosofía y política, y el rol que Platón cumple en la conformación y disgregación de ambas bajo su perspectiva y proyecciones.

\section{2.- Filosofía y política}

Arendt al hablar de política retoma el concepto griego de polis destacando que la ciudad-estado se basa en

La organización de la gente tal como surge de actuar y hablar juntos, y su verdadero espacio se extiende entre las personas que viven juntas para este propósito, sin importar dónde estén... [por lo que] la acción y el discurso crean un espacio entre los participantes que pueden encontrar su propia ubicación en todo tiempo y lugar... [Concluyendo que] Se trata del espacio de aparición en el más amplio sentido de la palabra, es decir, el espacio donde yo aparezco ante otros como otros aparecen ante mí, donde los hombres no existen meramente como otras cosas vivas o inanimadas, sino que hacen su aparición de manera explícita (Arendt, 2013, p. 221) ${ }^{20}$.

Para ella, humana y políticamente hablando, se identifica realidad con aparición: Ser es Apariencia ${ }^{21}$. Al comentar los dos significados de la palabra "público" (el primero Apariencia-Realidad y el segundo, Mundo [Arendt, 2013, p. 59 - 67]), Arendt (2013, p. 59 - 60) expresa del primero que

Todo lo que aparece en público puede verlo y oírlo todo el mundo y tiene la más amplia publicidad posible. Para nosotros [dice ella], la apariencia - algo que ven y oyen otros al igual que nosotros constituye la realidad ... La presencia de otros que ven lo que vemos y oyen lo que oímos nos asegura la realidad del mundo y de nosotros mismos, y puesto que la intimidad de una vida privada plenamente desarrollada... siempre intensifica y enriquece grandemente toda la escala de emociones subjetivas y sentimientos privados, esta intensificación se produce a expensas de la seguridad en la realidad del

20 Cf. Arendt, 2013, p. 39 - 41, 43 - 44, 53, 219 - 220.

21 Cf. Arendt, 2014b, p. 43 - 90, especialmente la p. 47. 
mundo y de los hombres 22 .

Justamente desde esto Arendt implementa la idea de esfera privada, aquella que nace bajo el sentido privativo de la pública ${ }^{23}$.

En base a esto, y al contrario de la esfera privada, la esfera política surge del actuar juntos, en lo que llama con Aristóteles "el compartir pa-

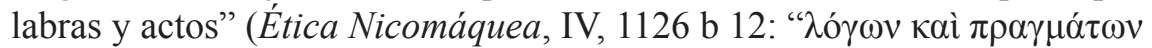

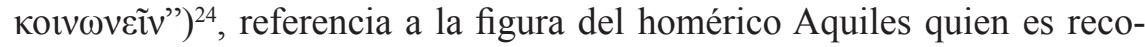
nocido como el "decidor de palabras y autor de hazañas" (Ilíada, IX, 443:

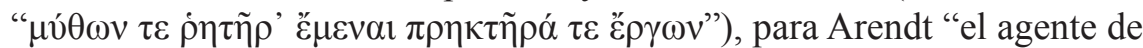
grandes acciones y el orador de grandes palabras" $\left(2013\right.$, p. 39) ${ }^{25}$, por lo que la acción constituye la actividad propia de la esfera política, de ese mundo común a todos. "Sólo la acción es prerrogativa exclusiva del hombre; ni una bestia ni un dios son capaces de ella, y sólo ésta depende por entero de la constante presencia de los demás", dice Arendt $(2013 \text {, p. } 38)^{26}$.

Aquí radica el problema. Los diversos intentos orientados a encontrar bases teóricas en torno al escape por completo de la esfera política debido a la fragilidad de los asuntos humanos (República, VI, 500 b - c:

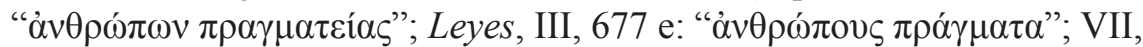

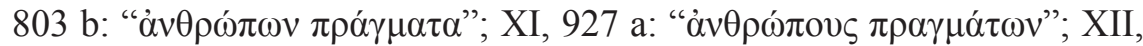
951 a: " $\alpha v \theta \rho \omega ́ \pi \omega v \pi \rho \alpha ́ \gamma \mu \alpha \tau \alpha ")^{27}$ para adentrarse en el terreno sólido de la quietud de la contemplación, surgen desde la filosofía política de Platón. En este punto nos encontramos con el concepto de gobierno. Arendt lo describe señalando que "los hombres solo pueden vivir juntos legal y políticamente cuando algunos tienen derecho a mandar y los demás se ven obligados a obedecer" (2013, p. 242) ${ }^{28}$.

22 Cf. Arendt, 2013, p. 66.

23 Cf. Arendt, 2013, p. 67.

24 Cf. Arendt, 2013, p. 219.

25 Arendt, 2013, p. 208 - 9.

26 Arendt 2006, p. 202. La autora parece remitir, aun cuando no lo cita, a Aristóteles (Política, 1, 2, 1.253 a 25-29).

27 Cf. Arendt, 2013, p. 32, 39, 80, 197, 209, 211 - 215, 242, 244, 246, 247, $250,252$.

28 Cf. Arendt, 2006, p. 458 - 9; 2016a, p. 74. 
Aquí nos topamos con la filosofía, y particularmente con la filosofía platónica desde la visión arendtiana, que en esta circunstancia se afirma principalmente de una distinción tratada en el Político $(305 \mathrm{c}-\mathrm{d})$ en la que "Platón abre una brecha entre los dos modos de acción, archein y prattein (“comienzo" y "actuación"), que según el pensamiento griego estaban relacionados" (Arendt, 2013, p. 243). Platón dice en dicho diálogo:

La ciencia que es verdaderamente real no debe actuar

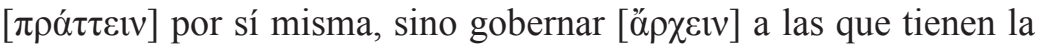
capacidad de actuar, ya que ella, en lo que toca a la oportunidad o inoportunidad, conoce el punto de partida y la puesta en marcha

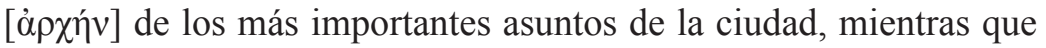
las demás deben hacer lo que les ha sido impuesto [ $\pi \rho 0 \sigma \tau \alpha \chi \theta \varepsilon \dot{\varepsilon} \tau \tau \alpha$ $\delta \rho \tilde{\alpha} v]$.

De acuerdo con la lectura que Arendt realiza del Político platónico, el problema consistía en precaverse de que aquel que realizara una acción seguiría siendo dueño completo de la misma, no requiriendo la ayuda de otros para ello. Tomando en cuenta que la acción siempre se da con otros, la única forma de lograr esto es considerar que los otros no necesitan unirse a la misma por acuerdo propio (con motivos y objetivos propios), pues estarían acostumbrados a ejecutar órdenes, considerando, además, que aquel que parte la acción (Arendt habla del "principiante") no se permite tomar compromiso de la misma. En este contexto, los dos modos de la acción ("comienzo" y "actuación") se tornan actividades diferentes; aquel que comienza la acción, el principiante, llega a ser un gobernante (’ó $\chi \omega)$ en ambos sentidos del término: " $<<$ no tiene que actuar (prattein), sino que gobierna (archein) sobre quienes son capaces de ejecutación $>>$ " (Arendt: 2013, p. 243; 2016a, p. 128 - 129). Con este matiz alcanzado, Arendt define la esencia de la política desde el prisma platónico: " $<<$ saber cómo comenzar y gobernar los asuntos más graves con respecto a oportunidad e inoportunidad $>>$; la acción como tal se ha eliminado totalmente y ha pasado a ser la simple <<ejecución de órdenes $>>$ " (2013, p. 243) ${ }^{29}$.

29 Cf. Arendt, 2006, p. 27; 2013, p. 200 - 205, 212 - 213, 227 y 265 - 266; 2014a, p. 44, 48, 69, 89, 137 - 8, 182, 198, 216 - 7, 306, 424 - 7. Véase Político $308 \mathrm{~d}-\mathrm{e}$. 
En este sentido, Platón fue el primero en ver esto y de ahí nace la tradición del pensamiento filosófico y político con esta brecha divisoria: los que saben no actúan y los que actúan no saben. Esa línea que disgrega acción y pensamiento fue identificada con la línea divisoria entre gobernantes y gobernados, al tiempo que su sustento es visto por Platón en su concepto de familia, comunidad básica en la que nada podía realizarse si el dueño de esta no sabía qué hacer y no era capaz de entregar órdenes a los esclavos (Arendt, 2016a, p. 89), las mismas que estos ejecutaban sin saber. Arendt sintetiza la idea expresando que "quien sabe no tiene que hacer y quien hace no necesita pensamiento ni conocimiento" (2013, p. 243). Es fácil entender con esto que Platón no quería abolir la familia, sino que más bien ampliar este formato de vida hasta que los ciudadanos formaran una "gran" familia, tratando de eliminar el carácter privado de la comunidad familiar, instando a la abolición del estatus marital individual y de la propiedad privada. Arendt condensa la profundidad de su intuición de la siguiente manera:

Según el pensamiento griego, la relación entre gobernar y ser gobernado, entre mando y obediencia, era por definición idéntica a la relación entre amo y esclavos y por consiguiente impedía toda posibilidad de acción. Por lo tanto, la argumentación de Platón de que las normas de conducta en los asuntos públicos debían derivarse de la relación amo-esclavo en una familia bien ordenada, significaba realmente que la acción no tenía que desempeñar parte alguna en los asuntos humanos. (2013, p. 244)

Detrás de esto sigue latente el concepto de gobierno que, aun cuando tiene su arraigo en el concepto de familia (centro de la desigualdad, al contrario de la polis, en la que solo era posible conocer "iguales") ${ }^{30}$, siempre ha desempeñado un rol fundamental en la organización de los asuntos públicos, estando intrínsecamente ligado a la política, a pesar de que para Platón era un elemento mucho más general ${ }^{31}$. En dicho concepto veía "el principal dispositivo para ordenar y juzgar los asuntos humanos en todo aspecto" dice Arendt (2013, p. 244), lo que resulta claro considerando su insistencia en que la ciudad-estado ha de ser entendida como un $<<$ amplio mandamiento del hombre $>>$, además de atender a la idea de que la cons-

30 Cf. Arendt, 2013, p. 44.

31 Cf. Arendt, 2013, p. 42. 
trucción de la misma está circunscrita a un orden psicológico que acompaña al orden público de la ciudad utópica ${ }^{32}$. De hecho, se desprende que él mismo introdujo el principio de dominación en orden al hombre consigo mismo $^{33}$. Esta es la causa de que, tanto en Platón como para la aristocrática tradición occidental, el principio para gobernar a los demás esté inspirado en la capacidad de poder gobernarse a sí mismo ${ }^{34}$. Con él, la identidad originaria entre comenzar y gobernar tuvo como consecuencia directa que "todo comienzo se entendió como legitimación de gobierno hasta que, finalmente, el factor comienzo desapareció por completo del concepto de gobierno... Con él desapareció de la filosofía política la comprensión más elemental y autentica de la libertad humana" (Arendt, 2013, p. 245).

\section{3.- Distinción entre hacer y fabricar. Lo bueno y lo hermoso}

La razón que sustenta la longevidad de la separación platónica entre saber y hacer estriba en que dio fuerza inigualable a la sustitución de gobierno por acción a través de la interpretación vinculante entre el hacer y el fabricar. Este anhelo fue previsto para alcanzar la solidez propia del trabajo y la fabricación en la esfera de los asuntos humanos, lo que, según la interpretación arendtiana, es visible al momento en que Platón "toca" la teoría de las ideas. Al momento de referirse a ellas en un plano no-político (Arendt recuerda el Banquete como ejemplo) las señala como aquello que

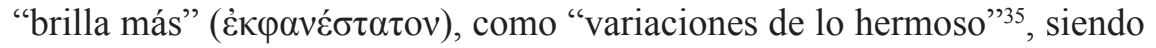
sólo en República donde las ideas cobran el sentido de modelos, medidas y normas de conducta, derivaciones de la idea de "lo bueno" griegamente hablando: adecuación o "lo bueno para" 36 . Este vuelco en el enfoque de la doctrina platónica tiene un interesante acento en la figura del filósofo en tanto amante de lo hermoso y del filósofo-rey (2016a, p. 122) y la Idea de bondad:

32 Cf. República, II, 368 e - 369 a; IV, 434 d - 435 a.

33 Cf. Arendt, 2013, p. $241-242$ y 257.

34 Cf. Arendt, 2013, p. 245: "para Platón... sólo el comienzo (archē) da derecho a gobernar (archein)".

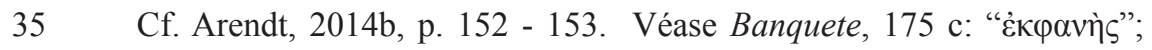

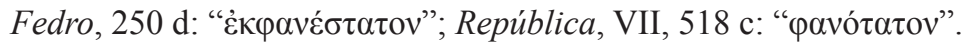

Cf. Arendt, 2006, p. 485. 
Esta transformación era necesaria para aplicar la doctrina de las ideas a la política, y debido esencialmente a un propósito político, el de eliminar el carácter de fragilidad de los asuntos humanos, Platón creyó preciso declarar lo bueno, y no lo hermoso, como la más elevada idea. Pero esta idea de lo bueno no es la más elevada del filósofo, quien desea contemplar la verdadera esencia del Ser y por consiguiente cambia la oscura caverna de los asuntos humanos por el brillante firmamento de las Ideas; incluso en la República, el filósofo sigue definido como amante de lo hermoso, no de lo bueno. La bondad es la más elevada idea del filósofo-rey, que desea gobernar los asuntos humanos porque ha de pasar su vida entre los hombres y no puede residir para siempre bajo el firmamento de las ideas. (Arendt, 2013, p. 246) ) $^{37}$

Lo que buscaba finalmente Platón con la aplicación de la doctrina de las ideas a la esfera política era eliminar el elemento personal de su gobierno ideal ${ }^{38}$. Es importante tener presente que Platón tenía clarísimo que sus imágenes sacadas de la vida familiar requerían en la figura del gobernante cualidades más propias de un dios que de un hombre con el fin de diferenciarlo de sus súbditos ${ }^{39}$. Contrario a esto, la forma de construir la esfera pública a la imagen de un objeto fabricado sólo implicaba la maestría y experiencia en el arte de la política ${ }^{40}$ al igual que en todas las artes, donde lo importante estriba en el objeto impersonal de dicho arte u oficio y no en el artista o artesano. Así es como para Arendt, "en la República, el filósofo-rey aplica las ideas al modo como el artesano lo hace con sus normas y modelos; $<<$ hace $>>$ su ciudad como el escultor una estatua" (2013, p. 247 $)^{41}$. Incluso en las Leyes platónicas estas ideas se convirtieron en leyes solo necesitando ser ejecutadas ${ }^{42}$, con lo que se termina de asentar la

37 Cf. Arendt, 2006, p . 482.

38 Cf. Arendt, 2006, p. 443, 445; 2016a, p. 46; 2016b, p. 178 - 180.

39 Cf. Político, 274 e -277 d, 303 b.

40 Cf. Arendt, 2013, p. 229 - 230.

41 Cf. República IV, 420 c.

42 Cf. Arendt, 2013, p. 247, nota n 69; 2016a, p. 100. Véase Fedón, 107d; República, X, 620d - 3; Político, 271d - e, 272e - 273b; Leyes, IV, 713b - 714a, 
base de toda una tradición de pensamiento político en la que el concepto de acción pasa a ser interpretado como formación y fabricación ${ }^{43}$.

\section{4.- Crítica a la filosofía política y filosofía de la historia}

Otro aspecto que se desprende del anterior, nuevamente en clave dicotómica, es la relación extremadamente cercana entre filosofía política y filosofía de la historia y cómo Platón influye en la conformación de esta relación. En el marco de la concepción arendtiana de identidad personal cuya base encuentra sustento en la esfera de los asuntos humanos, tanto en los intereses en los que las personas se relacionan y unen como en la trama en la que los hombres actúan y hablan para otros ${ }^{44}$, surge el tratamiento de la historia. En palabras de Arendt, "las historias, resultados de la acción y el discurso, revelan un agente, pero este agente no es autor o productor" (2013, p. 208). Para explicar esto, debemos considerar que la propia esfera de los asuntos humanos está constituida por la trama de relaciones que estos componen, la que existe en la medida que los hombres viven juntos, con lo que dicha trama establece el suelo en el que el agente se revela y establece un nuevo comienzo con su acción, la cual va encaminada a la realización de un propósito, pero esto no se agota aquí. Arendt asigna una importancia capital a la noción de trama, ya que señala que en dicho medio se producen historias de manera tan natural como en la fabricación se producen cosas tangibles, aun cuando una historia nos revela mucho más de su agente que un producto generado a partir de un maestro productor.

Ahora podemos volver a la idea de que las historias revelan un agente que no es autor ni productor. ¿Por qué? Que alguien comience una acción no implica que es su autor ni productor, no obstante, sí es su protagonista en un doble sentido, de actor y paciente. De ahí el papel de la historia a partir de la trama; la historia, arendtianamente hablando, es "la gran narración sin comienzo ni fin" (Arendt, 2013, p. 208), la cual posibilita que toda vida humana sea contable como una narración con comienzo y fin, siendo esta la condición prepolítica y prehistórica de la propia historia. Por esto, lo fundamental radica en que tanto la narración de una vida humana como las narraciones de la humanidad son resultado de la acción. Aquí aparece

\footnotetext{
$\mathrm{X}, 903 \mathrm{~b}-\mathrm{c}$.
} 
el problema. La acción funciona como categoría límite entre la filosofía de la historia en la Época Moderna ${ }^{45}$ y la filosofía política. Arendt (2013, p. 2208) lo expresa diciendo que:

El gran desconocido de la historia, que ha desconcertado a la filosofía de la historia en la Época Moderna, no surge cuando uno considera la historia como un todo y descubre que su protagonista, la humanidad, es una abstracción que nunca puede llegar a ser un agente activo; el mismo desconocido ha desconcertado a la filosofía política desde su comienzo en la antigüedad y contribuido al general desprecio que los filósofos desde Platón han tenido por la esfera de los asuntos humanos.

Platón, que es mencionado rápidamente en la cita, tiene un papel crucial. En toda serie de acontecimientos (los que juntos forman "una historia con un único significado") ${ }^{46}$, a lo más es posible establecer el agente que puso el proceso en movimiento, y aunque con frecuencia este agente es el protagonista, para Arendt no resulta posible establecerlo como el autor de la historia en cuestión. ¿Por qué Platón estaría presente en esta idea? Arendt lo destaca pues este pensaba que los asuntos humanos, aquellos que son resultado de la acción, no debiesen tratarse con seriedad. A propósito de esto, Arendt recuerda las Leyes platónicas (I, 644 d - 645 c; VII, 803 c) donde el hombre parece ser un juguete de dios, y las acciones de estos se parecen a las de marionetas guiadas por una mano invisible tras la escena ${ }^{47}$. Resulta muy interesante apreciar cómo Platón, que, por supuesto no tenía noción de la historia al modo moderno, "haya sido el primero en inventar la metáfora de un actor tras la escena que, a espaldas de los hombres que actúan, tira de los hilos y es responsable de la historia" (Arendt, 2013, p. 209). En este punto encontramos la noción de dios platónico, noción que según Arendt no es más que un símbolo, ya que las historias reales no tienen autor, a diferencia de aquellas que inventamos. Así es como Arendt considera que esta noción platónica

$45 \quad$ Cf. Arendt, 2013, p. 18 y 296.

46 Cf. Arendt, 2013, p. 208, 111.

47 Cf. Arendt, 2014b, p. 412 - 413; 2016a, p. 93 - 94. 
Es el verdadero precursor de la Providencia, la $<<$ mano invisible $>>$, la Naturaleza, el $<<$ espíritu del mundo $>>$, el interés de clase, y demás, con los que los filósofos cristianos y modernos intentaron resolver el problema de que si bien la historia debe su existencia a los hombres, no es $<<$ hecha $>>$ por ellos (2013, p. 209).

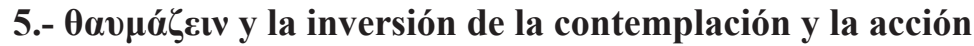

En el contexto de su crítica a la modernidad, de su estudio de la vita activa y de sus transformaciones de la misma, Arendt destaca un hecho fundacional que diferencia la actitud filosófica de la antigüedad respecto de la modernidad: así como "la extrañeza de que todo sea como es" fue la actitud griega filosóficamente hablando ${ }^{48}$, la duda cartesiana se presenta como la actitud filosófica de la modernidad. Es importante destacar que thaumazein se mantuvo como actitud filosófica hasta la modernidad sin variaciones profundas, mostrando longeva importancia y siendo una de las fuentes de la contemplación (cuya otra fuente es la aplicación de la doctrina de las ideas de Platón a ejemplos basados en las experiencias del artesano ${ }^{49}$. "El pasmo ante el milagro del Ser, es el comienzo de toda filosofía", dice Arendt con convicción (2013, p. 327), pasmo que, probablemente, sería esencialmente silencioso e intraducible en palabras ${ }^{50}$. Tanto Platón (Tee-

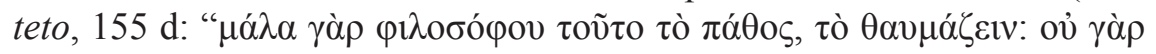

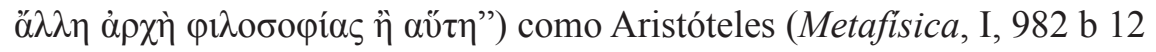

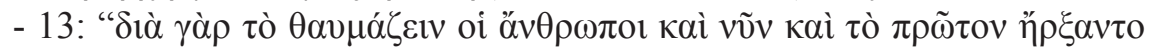

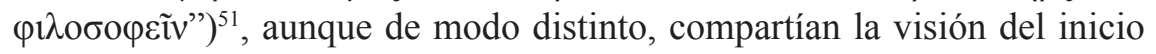
de la filosofía en el que el fin de la misma era la muda contemplación, con lo que se concreta la actitud fundamental: "la contemplación de la verdad a la que finalmente llega el filósofo es el mudo pasmo, filosóficamente purificado, con el que empezó" (Arendt: 2013, p. 328). Por lo que para Arendt $\theta \varepsilon \omega \rho i ́ \alpha$ no es más que otra forma de decir $\theta \alpha v \mu \alpha ́ \zeta \varepsilon ı v$. En este punto encontramos el choque con la modernidad y la inversión a su haber.

48 Cf. Arendt, 2014b, p. 164 - 174; 2016b, p. 183 - 184.

49 Cf. Arendt, 2013, p. 328.

50 Cf. Arendt, 2013, p. 32.

51 Cf. Arendt 2014b, p. 137 - 144; 2016a, p. 69 - 75. Véase Metafisica, I,

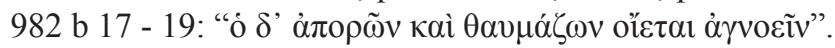


Para Arendt, la más importante consecuencia de los descubrimientos de la Época Moderna fue la inversión del orden jerárquico entre la vita contemplativa y la vita activa (2013, p. 314). Si somos serios en el razonamiento, la inversión afectó solo a la relación entre pensamiento y acción, ya que la contemplación fue eliminada por completo. En este punto Arendt vuelve a Platón una vez más, para distinguir entre pensamiento y contemplación. El pensamiento es concebido como "el camino más directo e importante que llevaba a la contemplación de la verdad" (Arendt, 2013, p. $316)^{52}$. Desde acá vuelve a destacar la noción de pensamiento en tanto diálogo interior en el que uno habla consigo, ahora bajo la óptica de este como aquel medio para preparar el alma y llevar la mente a la contemplación de la verdad que es incomunicable mediante palabras, como diría Platón

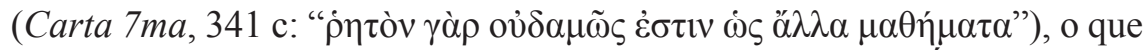
se encuentra más allá del discurso, como diría Aristóteles (Ética Nicomáquea, VI, 1142 a 25 y ss., y 1143 a 36 y ss.).

Platón, en ese sentido, fue crucial en la inversión de la Época Moderna, pero justo de manera contraria a como se dio en la tradición. La inversión que tuvo lugar en la Época Moderna estribaba en situar a la acción en el rango de la contemplación entendiendo la primera como el estado más alto del ser humano, así

Como si en adelante la acción fuera el significado último en virtud del cual tenía que interpretarse la contemplación, al igual que, hasta ese tiempo, todas las actividades de la vita activa se habían juzgado y justificado en la medida en que hacían posible la vita contemplativa. (Arendt, 2013, p. 317)

Con esta inversión que solo afectó al pensamiento, la contemplación se vació de significación por completo. Lo interesante de esto reside en que justamente esta inversión quedó oscurecida por otra que, desde Platón, ha imperado en toda la historia del pensamiento occidental, con la que, incluso, es constantemente identificada. Se trata de la inversión de Homero realizada por Platón desde la alegoría de la caverna de la República (VII, 514 a y ss. $)^{53}$ bajo el contexto de la historia griega. Platón habla en términos estrictos del giro que se exige al filósofo (República, VII, 521

$52 \quad$ Cf. Arendt, 2013, p. $186-188$.

53 Cf. Arendt, 2016a, p. $66-69$. 


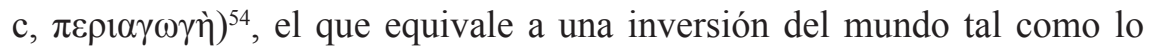
concibe Homero. Ahora es la vida común y corriente en la Tierra la que se ubica en una caverna, en un averno, y no la vida tras la muerte como en el Hades que narra Homero en la Odisea (XI, 477 y ss.). Ahora es el cuerpo la sombra del alma y no el alma la sombra del cuerpo. Ahora lo que no tiene sentido se aplica a las acciones de los hombres que no abandonan la caverna para contemplar las ideas eternas, papel que antes era atribuido al movimiento sin sentido de la existencia sin vida del alma tras la muerte en el Hades homérico. Lo que se hace importante destacar es que la tradición platónica de pensamiento filosófico y político comienza con esta inversión, determinando buena parte de los modelos de pensamiento en los que buceó por efecto la filosofía occidental, o al menos, aquella filosofía que no fue impulsada por la originalidad de un espíritu robustamente creativo ${ }^{55}$. Como dice Arendt (2013, p. 318):

Lo que aquí importa es la invertibilidad de todos estos sistemas, que se pueden poner hacia arriba o hacia abajo en cualquier momento de la historia sin requerir acontecimientos históricos 0 cambios en los elementos estructurales. Los propios conceptos siguen siendo lo mismo cualquiera sea el lugar donde se les coloque en los varios ordenes sistemáticos.

Justamente en esto Platón tiene un papel central, ya que en tanto logra hacer invertibles los conceptos y elementos estructurales, las inversiones dentro del curso de la historia intelectual ya no necesitarían algo más que la mera experiencia intelectual basada en el pensamiento conceptual específicamente. Así se dio con la tradición filosófica occidental, la que ha sido regida de esta forma, alternadamente por sus antítesis, y que en la Época Moderna cuenta con las inversiones de las jerarquías espirituales, como la de Marx y su vuelco de la dialéctica hegeliana, o la de Nietzsche y su oposición de lo natural y sensual con lo supranatural y suprasensual.

$54 \quad$ Cf. Arendt, 2006, p. 719.

55 Cf. Arendt, 2016b, p. 59 - 62, p. 202 - 212; 2018, p. 546 - 550. 


\section{Conclusión}

Con todo, "el pensamiento... todavía es posible, y sin duda real, siempre que los hombres vivan bajo condiciones de libertad política" dice Arendt (2013, p. 348). Esta es quizá la más grande lección que nuestra autora hereda para el posterior desarrollo de la filosofía y de la política; esta es quizá la herencia que sigue su curso en ella desde la propia fuente platónica, sea a favor o en contra.

En ocasión al congreso realizado en su honor en 1972, Hannah Arendt (2010, p. 69), a propósito de la pregunta del profesor C. B. Macpherson sobre el compromiso en una causa de un teórico político, señala con cierta desazón:

El principal defecto y error de La condición humana consiste en que en dicha obra sigo examinando lo que la tradición denomina vita activa desde el punto de vista de la vita contemplativa, sin decir nada real sobre la propia vita contemplativa.

Sin duda, esta idea es la que cimienta el interés por un "segundo tomo" de La condición humana; con esto, La vida del espíritu, en proceso de escritura en ese mismo momento, se instala como una necesidad. Quizás, por el propio influjo platónico en la tradición filosófica: "Todas las historias que hacen los primeros filósofos hombres que profesaron conscientemente el ideal $\theta \varepsilon \omega \rho \eta \tau$ เós $\beta$ B́os, o bien proceden directamente de la escuela platónica, o bien surgieron bajo el influjo del ideal platónico en los tiempos inmediatamente subsiguientes" (Jaeger, 2001, p. 471).

Visto lo anterior, Platón es, simplemente, esencial en Arendt, represente este un "trauma" o no (Dolan, 2009, p. 261 - 264). Él representa la conceptualización, base, distinción, problematización y proyección de la hostil y cercana relación entre filosofía y política en la que surge y se desarrolla la preocupación arendtiana sobre la problemática tratada. Ambas parecen friccionarse intentando superponerse una a la otra ininterrumpidamente; ambas parecen reflejarse y esconderse mutuamente; ambas parecen distanciarse encontrándose de espaldas; sobre todo, ambas eran las preocupaciones que daban vida a Platón y Arendt. 


\section{REFERENCIAS BIBLIOGRÁFICAS}

AGUSTÍN, SAN (2007). Obras completas, XVI. La ciudad de Dios (1. ${ }^{\circ}$. B.A.C., Madrid.

--- (2007). Obras completas, XVII. La ciudad de Dios (2. ${ }^{\circ}$. B.A.C., Madrid.

ARENDT, H. (1997). Filosofia y politica. Heidegger y existencialismo. Besatari, Bilbao.

--- (2006). Diario filosófico, 1950-1973. Notas y apéndices. Herder, Barcelona.

--- (2009). Conferencias sobre la filosofía política de Kant. Paidós, Buenos Aires.

--- (2010). Lo que quiero es comprender. Sobre mi vida y mi obra. Trotta, Madrid.

--- (2011). Los orígenes del totalitarismo. Alianza editorial, Madrid.

--- (2013): La condición humana. Paidós, Barcelona.

--- (2014a). Eichmann en Jerusalén. Un estudio acerca de la banalidad del mal. Debolsilo, Barcelona.

--- (2014b). La vida del espiritu. Paidós, Barcelona.

--- (2015a). Crisis de la República. Editorial Trotta, Madrid.

--- (2015b). Responsabilidad y juicio. Paidós, Barcelona.

--- (2016a). La promesa de la política. Paidós, Barcelona.

--- (2016b). Entre el pasado y el futuro. Ocho ejercicios sobre la reflexión política. Ariel, Buenos Aires.

--- (2018). Ensayos de comprensión, 1930 - 1954: formación, exilio y totalitarismo. Página indómita, Barcelona.

ARISTÓTELES (2008). Ética nicomáquea - Ética eudemia. Editorial Gredos, Madrid.

--- (2018). Metafísica. Editorial Gredos, Madrid.

BIRULÉS, F. (2007). Una herencia sin testamento: Hannah Arendt. Herder Editorial, Barcelona.

CALVO MARTÍNEZ, T. (2004). "Sócrates: Tomás Calvo Martínez”, en Historia de la Filosofía Antigua, Carlos García Gual (ed.). Editorial Trotta, Madrid.

CAMPILLO, N. (2013). Hannah Arendt: lo filosófico y lo político. Universidad de València, València.

CORNFORD, F. M. (1950). The unwritten philosophy and other essays. Cambridge University Press.

DOLAN, F. (2009). "Arendt on philosophy and politics", en The Cambridge Companion to Hannah Arendt, Dana Villa (ed.). Cambridge University Press, Cambridge.

FORTI, S. (2001). Vida del espiritu y tiempo de la polis. Hannah Arendt entre filosofía y política. Ediciones Cátedra, Madrid. 
GARCÍA CUAL, C. (2017). "Capitulo I. La Grecia antigua, Carlos García Gual”, en Historia de la Teoría Política, 1, Fernando Vallespín (ed.). Alianza Editorial, Madrid.

GUTHRIE, W. K. C. (1994a). Los filósofos griegos. De Tales de Aristóteles. Fondo de Cultura Económica, Santiago de Chile.

--- (1994b). Historia de la filosofía griega III: Siglo V. Ilustración. Editorial Gredos, Madrid.

HEGEL, G. W. F. (1995). Lecciones sobre la historia de la filosofía II. Fondo de Cultura Económica, México, D. F.

HOMERO (2006). Ilíada. Editorial Gredos, Madrid.

--- (2006). Odisea. Editorial Gredos, Madrid.

JAEGER, W. (2001). Aristóteles. Bases para la historia de su desarrollo intelectual. Fondo de Cultura Económica, México, D. F.

--- (2006). Paideia: los ideales de la cultura griega. Fondo de Cultura Económica, México, D. F.

MUNDO, D. (2008). "El valor de pensar", en Hannah Arendt, el legado de una mirada, VV. AA. Ediciones sequitur, Madrid.

PLATÓN (1981 - 1999). Diálogos. Traductores varios [9 vol.]. Editorial Gredos, Madrid.

--- (1889 - 1995). Platonis Opera. J. Burnet y otros editores, [5 Vol.]. Oxford University Press: Oxford.

VILLA, D. R. (2008). “Arendt y Sócrates", en Hannah Arendt, el legado de una mirada, VV. AA. Ediciones sequitur, Madrid. 